\title{
Convergence theorems for equilibrium problem and asymptotically quasi- $\phi$-nonexpansive mappings in the intermediate sense
}

\section{Jae Ug Jeong*}

"Correspondence:

jujeong@deu.ac.kr Department of Mathematics,

Dongeui University, Busan, 614-714, South Korea

\begin{abstract}
In this paper, we introduce an iterative process which converges strongly to a common element of the set of fixed points of an asymptotically quasi- $\boldsymbol{\phi}$-nonexpansive mapping in the intermediate sense and the solution set of generalized equilibrium problem in Banach spaces. Our theorems improve, generalize, and extend several results recently announced.

MSC: $47 \mathrm{H} 05 ; 47 \mathrm{H} 09 ; 47 \mathrm{H} 10$
\end{abstract}

Keywords: fixed point; asymptotically quasi- $\phi$-nonexpansive mapping; generalized $f$-projection operator; relatively nonexpansive mapping

\section{Introduction}

Let $E$ be a real Banach space with the dual space $E^{*}$. Let $C$ be a nonempty closed convex subset of $E$. Let $T: C \rightarrow C$ be a nonlinear mapping. We denote by $F(T)$ the set of fixed points of $T$.

A mapping $T$ is said to be asymptotically nonexpansive if there exists a sequence $\left\{k_{n}\right\} \subset$ $[1, \infty)$ with $k_{n} \rightarrow 1$ as $n \rightarrow \infty$ such that

$$
\left\|T^{n} x-T^{n} y\right\| \leq k_{n}\|x-y\|, \quad \forall x, y \in C, n \geq 1 .
$$

The class of asymptotically nonexpansive mappings was introduced by Goebel and Kirk [1] in 1972. In uniformly convex Banach spaces, they proved that if $C$ is nonempty, bounded, closed, and convex, then every asymptotically nonexpansive self-mapping $T$ on $C$ has a fixed point. Further, the fixed point set of $T$ is closed and convex.

A mapping $T$ is said to be asymptotically nonexpansive in the intermediate sense (see [2]) if it is continuous and the following inequality holds:

$$
\limsup _{n \rightarrow \infty} \sup _{x, y \in C}\left(\left\|T^{n} x-T^{n} y\right\|-\|x-y\|\right) \leq 0 .
$$

If $F(T) \neq \phi$ and (1.1) holds for all $x \in K, y \in F(T)$, then $T$ is called asymptotically quasinonexpansive in the intermediate sense. It is well known that if $C$ is a nonempty closed

(02014 Jeong; licensee Springer. This is an Open Access article distributed under the terms of the Creative Commons Attribution License (http://creativecommons.org/licenses/by/2.0), which permits unrestricted use, distribution, and reproduction in any medium, provided the original work is properly cited. 
convex bounded subset of a uniformly convex Banach space $E$ and $T$ is a self-mapping of $C$ which is asymptotically nonexpansive in the intermediate sense, then $T$ has a fixed point (see [3]). It is worth mentioning that the class of mappings which are asymptotically nonexpansive in the intermediate sense contains properly the class of asymptotically nonexpansive mappings.

Iterative approximation of a fixed point for asymptotically nonexpansive mappings in Hilbert or Banach spaces has been studied extensively by many authors (see [4-6] and the references therein).

Let $E$ be a smooth Banach space. The function $\phi: E \times E \rightarrow \mathbb{R}$ defined by

$$
\phi(x, y)=\|x\|^{2}-2\langle x, J y\rangle+\|y\|^{2}, \quad \forall x, y \in E,
$$

is studied by Alber [7]. It follows from the definition of $\phi$ that

$$
(\|x\|-\|y\|)^{2} \leq \phi(x, y) \leq(\|x\|+\|y\|)^{2}, \quad \forall x, y \in E .
$$

\section{Remark 1.1}

(i) If $E$ is a reflexive, strictly convex and smooth Banach space, then for $x, y \in E$, $\phi(x, y)=0$ if and only if $x=y$.

(ii) If $E$ is a real Hilbert space, then $\phi(x, y)=\|x-y\|^{2}$.

Let $E$ be reflexive, strictly convex and smooth Banach space. The generalized projection mapping, introduced by Alber [7], is a mapping $\Pi_{C}: E \rightarrow C$ that assigns to an arbitrary point $x \in E$ the minimum point of the functional $\phi(y, x)$, that is, $\Pi_{C} x=\bar{x}$, where is $\bar{x}$ is the solution to the minimization problem

$$
\phi(\bar{x}, x)=\inf _{y \in C} \phi(y, x)
$$

A point $p$ in $C$ is said to be an asymptotic fixed point of $T$ if $C$ contains a sequence $\left\{x_{n}\right\}$ which converges weakly to $p$ such that $\lim _{n \rightarrow \infty}\left\|x_{n}-T x_{n}\right\|=0$. The set of asymptotic fixed points of $T$ will be denoted by $\tilde{F}(T)$. A mapping $T$ is called relatively nonexpansive (see [8]) if $\tilde{F}(T)=F(T)$ and $\phi(p, T x) \leq \phi(p, x)$ for all $x \in C$ and $p \in F(T)$.

Recently, Matsushita and Takahashi [9] proved strong convergence theorems for approximation of fixed points of relatively nonexpansive mappings in a uniformly convex and uniformly smooth Banach space. More precisely, they proved the following theorem.

Theorem 1.1 Let E be a uniformly convex and uniformly smooth Banach space, let $C$ be a nonempty closed convex subset of $E$, let $T$ be a relatively nonexpansive mapping from $C$ into itself and let $\left\{\alpha_{n}\right\}$ be a sequence of real numbers such that $0 \leq \alpha_{n} \leq 1$ and $\lim _{\sup } \operatorname{su}_{n \rightarrow \infty} \alpha_{n}<1$. Suppose that $\left\{x_{n}\right\}$ is given by

$$
\left\{\begin{array}{l}
x_{0}=x \in C, \\
y_{n}=J^{-1}\left(\alpha_{n} J x_{n}+\left(1-\alpha_{n}\right) J T x_{n}\right), \\
H_{n}=\left\{z \in C: \phi\left(z, y_{n}\right) \leq \phi\left(z, x_{n}\right)\right\}, \\
W_{n}=\left\{z \in C:\left\langle x_{n}-z, J x-J x_{n}\right\rangle \geq 0\right\}, \\
x_{n+1}=\Pi_{H_{n} \cap W_{n}} x_{0}, \quad n=0,1,2, \ldots,
\end{array}\right.
$$


where $J$ is the normalized duality mapping on E. If $F(T)$ is nonempty, then $\left\{x_{n}\right\}$ converges strongly to $\Pi_{F(T)} x_{0}$.

In [10], Hao introduced the following iterative scheme for approximating a fixed point of asymptotically quasi- $\phi$-nonexpansive mappings in the intermediate sense in a reflexive, strictly convex and smooth Banach space $E: x_{0} \in E, C_{1}=C, x_{1}=\Pi_{C_{1}} x_{0}$,

$$
\left\{\begin{array}{l}
y_{n}=J^{-1}\left(\alpha_{n} J x_{n}+\left(1-\alpha_{n}\right) J T^{n} x_{n}\right), \\
C_{n+1}=\left\{z \in C_{n}: \phi\left(z, y_{n}\right) \leq \phi\left(z, x_{n}\right)+\xi_{n}\right\} \\
x_{n+1}=\Pi_{C_{n+1}} x_{1}, \quad n=1,2, \ldots,
\end{array}\right.
$$

where $\xi_{n}=\max \left\{0, \sup _{p \in F(T), x \in C}\left(\phi\left(p, T^{n} x\right)-\phi(p, x)\right)\right\}$.

Motivated and inspired by the works mentioned above, in this paper, we introduce a new iterative scheme of the generalized $f$-projection operator for finding a common element of the set of fixed points of asymptotically quasi- $\phi$-nonexpansive mappings in the intermediate sense and the solution set of generalized equilibrium problem in a uniformly smooth and strictly convex Banach space with the Kadec-Klee property.

\section{Preliminaries}

Let $E$ be a real Banach space with the norm $\|\cdot\|$ and let $E^{*}$ be the dual space of $E$. The normalized duality mapping $J: E \rightarrow 2^{E^{*}}$ is defined by

$$
J(x)=\left\{f \in E^{*}:\langle x, f\rangle=\|x\|^{2}=\|f\|^{2}\right\} .
$$

By the Hahn-Banach theorem, $J(x)$ is nonempty.

A Banach space $E$ is called strictly convex if $\left\|\frac{x+y}{2}\right\|<1$ for all $x, y \in U$ with $x \neq y$, where $U=\{x \in E:\|x\|=1\}$ is the unit sphere of $E$. A Banach space $E$ is called smooth if the limit

$$
\lim _{t \rightarrow \infty} \frac{\|x+t y\|-\|x\|}{t}
$$

exists for each $x, y \in U$. It is also called uniformly smooth if the limit exists uniformly for all $x, y \in U$. In this paper, we denote the strong convergence and weak convergence of a sequence $\left\{x_{n}\right\}$ by $x_{n} \rightarrow x$ and $x_{n} \rightarrow x$, respectively.

Remark 2.1 The basic properties of a Banach space $E$ related to the normalized duality mapping $J$ are as follows (see [11]):

(1) If $E$ is a smooth Banach space, then $J$ is single-valued and semicontinuous;

(2) If $E$ is a uniformly smooth Banach space, then $J$ is uniformly norm-to-norm continuous on each bounded subset of $E$;

(3) If $E$ is a uniformly smooth Banach space, then $E$ is smooth and reflexive;

(4) If $E$ is a reflexive and strictly convex Banach space, then $J^{-1}$ is norm-weak*-continuous;

(5) $E$ is a uniformly smooth Banach space if and only if $E^{*}$ is uniformly convex.

Recall that a Banach space $E$ has the Kadec-Klee property if for any sequence $\left\{x_{n}\right\} \subset E$ and $x \in E$ with $x_{n} \rightarrow x$ and $\left\|x_{n}\right\| \rightarrow\|x\|$, then $\left\|x_{n}-x\right\| \rightarrow 0$ as $n \rightarrow \infty$. It is well known that if $E$ is a uniformly convex Banach space, then $E$ has the Kadec-Klee property. 
Definition 2.1 A mapping $T: C \rightarrow C$ is said to be

(1) quasi- $\phi$-nonexpansive if $F(T) \neq \phi$ and

$$
\phi(p, T x) \leq \phi(p, x)
$$

for all $x \in C$ and $p \in F(T)$;

(2) asymptotically quasi- $\phi$-nonexpansive in the intermediate sense if $F(T) \neq \phi$ and

$$
\limsup _{n \rightarrow \infty} \sup _{p \in F(T), x \in C}\left(\phi\left(p, T^{n} x\right)-\phi(p, x)\right) \leq 0
$$

put

$$
\xi_{n}=\max \left\{0, \sup _{p \in F(T), x \in C}\left(\phi\left(p, T^{n} x\right)-\phi(p, x)\right)\right\} .
$$

Remark 2.2 From the definition of asymptotically quasi- $\phi$-nonexpansiveness in the intermediate sense, it is obvious that $\xi_{n} \rightarrow 0$ as $n \rightarrow \infty$ and

$$
\phi\left(p, T^{n} x\right) \leq \phi(p, x)+\xi_{n}, \quad \forall p \in F(T), x \in C .
$$

Recall that $T$ is said to be asymptotically regular on $C$ if for any bounded subset $K$ of $C$,

$$
\limsup _{n \rightarrow \infty}\left\{\left\|T^{n+1} x-T^{n} x\right\|: x \in K\right\}=0 .
$$

Definition 2.2 A mapping $T: C \rightarrow C$ is said to be closed if for any sequence $\left\{x_{n}\right\} \subset C$ with $x_{n} \rightarrow x$ and $T x_{n} \rightarrow y, T x=y$.

Following Alber [7], the generalized projection $\Pi_{C}: E \rightarrow C$ is defined by

$$
\Pi_{C}(x)=\left\{u \in C: \phi(u, x)=\min _{y \in C} \phi(y, x)\right\}, \quad \forall x \in E .
$$

In 2006, Wu and Huang [12] introduced a generalized $f$-projection operator in a Banach space, which extends the definition of the generalized projection $\Pi_{C}$. Let $G: C \times E^{*} \rightarrow$ $\mathbb{R} \cup\{+\infty\}$ be a functional defined as follows:

$$
G(y, \bar{w})=\|y\|^{2}-2\langle y, \bar{w}\rangle+\|\bar{w}\|^{2}+2 \rho f(y)
$$

for all $(y, \bar{w}) \in C \times E^{*}$, where $\rho$ is a positive number and $f: C \rightarrow \mathbb{R} \cup\{+\infty\}$ is proper, convex, and lower semicontinuous. From the definition of $G$, it is easy to see the following properties:

(i) $G(y, \bar{w})$ is convex and continuous with respect to $\bar{w}$ when $y$ is fixed;

(ii) $G(y, \bar{w})$ is convex and lower semicontinuous with respect to $y$ when $\bar{w}$ is fixed.

Definition 2.3 ([13]) Let $E$ be a real smooth Banach space and let $C$ be a nonempty closed and convex subset of $E$. We say that $\Pi_{C}^{f}: E \rightarrow 2^{C}$ is a generalized $f$-projection operator if

$$
\Pi_{C}^{f} x=\left\{u \in C: G(u, J x)=\inf _{y \in C} G(y, J x), \forall x \in E\right\} .
$$


Lemma 2.1 ([14]) Let $E$ be a Banach space and $f: E \rightarrow \mathbb{R} \cup\{+\infty\}$ be a lower semicontinuous and convex function. Then there exist $x^{*} \in E^{*}$ and $\alpha \in \mathbb{R}$ such that

$$
f(x) \geq\left\langle x, x^{*}\right\rangle+\alpha
$$

for all $x \in E$.

Lemma 2.2 ([13]) Let E be a reflexive smooth Banach space and let $C$ be a nonempty closed convex subset of $E$. The following statements hold:

(1) $\Pi_{C}^{f} x$ is a nonempty closed convex subset of $C$ for all $x \in E$;

(2) For all $x \in F, \bar{x} \in \Pi_{C}^{f} x$ if and only if

$$
\langle\bar{x}-y, J x-J \bar{x}\rangle+\rho f(y)-\rho f(\bar{x}) \geq 0
$$

for all $y \in C$;

(3) If $E$ is strictly convex, then $\Pi_{C}^{f}$ is a single-valued mapping.

Let $\theta$ be a bifunction from $C \times C$ to $\mathbb{R}$, where $\mathbb{R}$ denotes the set of real numbers. The equilibrium problem is to find $\bar{x} \in C$ such that

$$
\theta(\bar{x}, y) \geq 0
$$

for all $y \in C$. The set of solutions of (2.1) is denoted by $E P(\theta)$.

For solving the equilibrium problem for a bifunction $\theta: C \times C \rightarrow \mathbb{R}$, let us assume that $\theta$ satisfies the following conditions:

(A1) $\theta(x, x)=0$ for all $x \in C$;

(A2) $\theta$ is monotone; i.e., $\theta(x, y)+\theta(y, x) \leq 0$ for all $x, y \in C$;

(A3) for all $x, y, z \in C$,

$$
\lim _{t \downarrow 0} \theta(t z+(1-t) x, y) \leq \theta(x, y)
$$

(A4) for all $x \in C, y \mapsto \theta(x, y)$ is convex and lower semicontinuous.

Lemma 2.3 ([15]) Let $C$ be a closed convex subset of a uniformly smooth, strictly convex, and reflexive Banach space $E$ and let $\theta$ be a bifunction from $C \times C$ to $\mathbb{R}$ satisfying the conditions (A1)-(A4). For all $r>0$ and $x \in E$, define a mapping $T_{r}^{\theta}: E \rightarrow C$ as follows:

$$
T_{r}^{\theta} x=\left\{z \in C: \theta(z, y)+\frac{1}{r}\langle y-z, J z-J x\rangle \geq 0, \forall y \in C\right\} .
$$

Then the following conclusions hold:

(1) $T_{r}^{\theta}$ is single-valued;

(2) $T_{r}^{\theta}$ is a firmly nonexpansive-type mapping, i.e., for all $x, y \in E$,

$$
\left\langle T_{r}^{\theta} x-T_{r}^{\theta} y, J T_{r}^{\theta} x-J T_{r}^{\theta} y\right\rangle \leq\left\langle T_{r}^{\theta} x-T_{r}^{\theta} y, J x-J y\right\rangle ;
$$

(3) $F\left(T_{r}^{\theta}\right)=E P(\theta)$ is closed and convex; 
(4) $T_{r}^{\theta}$ is quasi- $\phi$-nonexpansive;

(5) $\phi\left(q, T_{r}^{\theta} x\right)+\phi\left(T_{r}^{\theta} x, x\right) \leq \phi(q, x), \forall q \in F\left(T_{r}^{\theta}\right)$.

Lemma 2.4 ([10]) Let $E$ be a reflexive, strictly convex and smooth Banach space such that both $E$ and $E^{*}$ have the Kadec-Klee property. Let $C$ be a nonempty closed convex subset of E. Let $T: C \rightarrow C$ be a closed and asymptotically quasi- $\phi$-nonexpansive mapping in the intermediate sense. Then $F(T)$ is a closed convex subset of $C$.

Lemma 2.5 ([13]) Let $E$ be a real reflexive smooth Banach space and let $C$ be a nonempty closed and convex subset of $E$. Then, for any $x \in E$ and $\bar{x} \in \Pi_{C}^{f}$,

$$
\phi(y, \bar{x})+G(\bar{x}, J x) \leq G(y, J x)
$$

for all $y \in C$.

\section{Main results}

Theorem 3.1 Let $E$ be a uniformly smooth and strictly convex Banach space with the Kadec-Klee property. Let $C$ be a nonempty closed convex subset of E. Let $\theta$ be a bifunction from $C \times C$ to $\mathbb{R}$ satisfying the conditions (A1)-(A4). Let $T: C \rightarrow C$ be a closed and asymptotically quasi- $\phi$-nonexpansive mapping in the intermediate sense. Assume that $T$ is asymptotically regular on $C, \mathcal{F}=F(T) \cap E P(\theta)$ is nonempty, and $F(T)$ is bounded. Let $f: E \rightarrow \mathbb{R}^{+}$be a convex and lower semicontinuous function with $C \subset \operatorname{int}(D(f))$ and $f(0)=0$. Let $\left\{\alpha_{n}\right\}$ be a sequence in $[0,1]$ and $\left\{\beta_{n}\right\},\left\{\gamma_{n}\right\}$ be sequences in $(0,1)$ satisfying the following conditions:

(i) $\alpha_{n}+\beta_{n}+\gamma_{n}=1$;

(ii) $\lim _{n \rightarrow \infty} \alpha_{n}=0$;

(iii) $0<\liminf _{n \rightarrow \infty} \beta_{n} \leq \limsup _{n \rightarrow \infty} \beta_{n}<1$.

Let $\left\{x_{n}\right\}$ be a sequence generated by

$$
\left\{\begin{array}{l}
x_{1} \in E \text { chosen arbitrarily, } \\
C_{1}=C \\
y_{n}=J^{-1}\left(\alpha_{n} J x_{1}+\beta_{n} J T^{n} x_{n}+\gamma_{n} J x_{n}\right), \\
u_{n} \in C \text { such that } \theta\left(u_{n}, y\right)+\frac{1}{r_{n}}\left\langle y-u_{n}, J u_{n}-J y_{n}\right\rangle \geq 0, \quad \forall y \in C, \\
C_{n+1}=\left\{z \in C_{n}: G\left(z, J u_{n}\right) \leq \alpha_{n} G\left(z, J x_{1}\right)+\left(1-\alpha_{n}\right) G\left(z, J x_{n}\right)+\xi_{n}\right\}, \\
x_{n+1}=\Pi_{C_{n+1}}^{f} x_{1}, \quad \forall n \geq 1
\end{array}\right.
$$

where $\xi_{n}=\max \left\{0, \sup _{p \in F(T), x \in C}\left(\phi\left(p, T^{n} x\right)-\phi(p, x)\right)\right\},\left\{r_{n}\right\}$ is a real sequence in $[a, \infty)$ for some $a>0$ and $\Pi_{C_{n+1}}^{f}$ is the generalized $f$-projection operator. Then $\left\{x_{n}\right\}$ converges strongly to $\Pi_{\mathcal{F}}^{f} x_{1}$.

Proof It follows from Lemma 2.3 and Lemma 2.4 that $\mathcal{F}$ is a closed convex subset of $C$, so that $\Pi_{\mathcal{F}}^{f} x$ is well defined for any $x \in C$.

We split the proof into six steps.

Step 1. We first show that $C_{n}$ is nonempty, closed, and convex for all $n \geq 1$.

In fact, it is obvious that $C_{1}=C$ is closed and convex. Suppose that $C_{n}$ is closed and convex for some $n \geq 2$. For $z_{1}, z_{2} \in C_{n+1}$, we see that $z_{1}, z_{2} \in C_{n}$. It follows that $z=t z_{1}+(1-$ 
$t) z_{2} \in C_{n}$, where $t \in(0,1)$. Notice that

$$
G\left(z_{1}, J u_{n}\right) \leq \alpha_{n} G\left(z_{1}, J x_{1}\right)+\left(1-\alpha_{n}\right) G\left(z_{1}, J x_{n}\right)+\xi_{n},
$$

and

$$
G\left(z_{2}, J u_{n}\right) \leq \alpha_{n} G\left(z_{2}, J x_{1}\right)+\left(1-\alpha_{n}\right) G\left(z_{2}, J x_{n}\right)+\xi_{n} .
$$

The above inequalities are equivalent to

$$
\begin{array}{r}
2 \alpha_{n}\left\langle z_{1}, J x_{1}\right\rangle+2\left(1-\alpha_{n}\right)\left\langle z_{1}, J x_{n}\right\rangle-2\left\langle z_{1}, J u_{n}\right\rangle \\
\leq \alpha_{n}\left\|x_{1}\right\|^{2}+\left(1-\alpha_{n}\right)\left\|x_{n}\right\|^{2}-\left\|u_{n}\right\|^{2}+\xi_{n}
\end{array}
$$

and

$$
\begin{gathered}
2 \alpha_{n}\left\langle z_{2}, J x_{1}\right\rangle+2\left(1-\alpha_{n}\right)\left\langle z_{2}, J x_{n}\right\rangle-2\left\langle z_{2}, J u_{n}\right\rangle \\
\leq \alpha_{n}\left\|x_{1}\right\|^{2}+\left(1-\alpha_{n}\right)\left\|x_{n}\right\|^{2}-\left\|u_{n}\right\|^{2}+\xi_{n} .
\end{gathered}
$$

Multiplying $t$ and $1-t$ on both sides of (3.2) and (3.3), respectively, we obtain

$$
\begin{aligned}
& 2 \alpha_{n}\left\langle z, J x_{1}\right\rangle+2\left(1-\alpha_{n}\right)\left\langle z, J x_{n}\right\rangle-2\left\langle z, J u_{n}\right\rangle \\
& \quad \leq \alpha_{n}\left\|x_{1}\right\|^{2}+\left(1-\alpha_{n}\right)\left\|x_{n}\right\|^{2}-\left\|u_{n}\right\|^{2}+\xi_{n} .
\end{aligned}
$$

Hence we have

$$
G\left(z, J u_{n}\right) \leq \alpha_{n} G\left(z, J x_{1}\right)+\left(1-\alpha_{n}\right) G\left(z, J x_{n}\right)+\xi_{n} .
$$

This implies that $C_{n+1}$ is closed and convex for all $n \geq 1$. This shows that $\Pi_{C_{n+1}}^{f} x_{1}$ is well defined.

Step 2. We show that $\mathcal{F} \subset C_{n}$ for all $n \geq 1$.

For $n=1$, we have $\mathcal{F} \subset C_{1}=C$. Now, assume that $\mathcal{F} \subset C_{n}$ for some $n \geq 2$. Let $q \in \mathcal{F}$. Since $T$ is asymptotically quasi- $\phi$-nonexpansive with intermediate sense, we have from Remark 2.2 and Lemma 2.3 that

$$
\begin{aligned}
G\left(q, J u_{n}\right)= & G\left(q, J T_{r_{n}}^{\theta} y_{n}\right) \\
= & \phi\left(q, T_{r_{n}}^{\theta} y_{n}\right)+2 \rho f(q) \\
\leq & \phi\left(q, y_{n}\right)+2 \rho f(q) \\
= & G\left(q, J y_{n}\right) \\
= & G\left(q, \alpha_{n} J x_{1}+\beta_{n} J T^{n} x_{n}+\gamma_{n} J x_{n}\right) \\
= & \|q\|^{2}-2 \alpha_{n}\left\langle q, J x_{1}\right\rangle-2 \beta_{n}\left\langle q, J T^{n} x_{n}\right\rangle-2 \gamma_{n}\left\langle q, J x_{n}\right\rangle \\
& +\left\|\alpha_{n} J x_{1}+\beta_{n} J T^{n} x_{n}+\gamma_{n} J x_{n}\right\|^{2}+2 \rho f(q) \\
\leq & \|q\|^{2}-2 \alpha_{n}\left\langle q, J x_{1}\right\rangle-2 \beta_{n}\left\langle q, J T^{n} x_{n}\right\rangle-2 \gamma_{n}\left\langle q, J x_{n}\right\rangle
\end{aligned}
$$




$$
\begin{aligned}
& +\alpha_{n}\left\|J x_{1}\right\|^{2}+\beta_{n}\left\|J T^{n} x_{n}\right\|^{2}+\gamma_{n}\left\|J x_{n}\right\|^{2}+2 \rho f(q) \\
= & \alpha_{n} G\left(q, J x_{1}\right)+\beta_{n} G\left(q, J T^{n} x_{n}\right)+\gamma_{n} G\left(q, J x_{n}\right) \\
= & \alpha_{n} G\left(q, J x_{1}\right)+\beta_{n}\left\{\phi\left(q, T^{n} x_{n}\right)+2 \rho f(q)\right\}+\gamma_{n} G\left(q, J x_{n}\right) \\
\leq & \alpha_{n} G\left(q, J x_{1}\right)+\beta_{n}\left\{\phi\left(q, x_{n}\right)+\xi_{n}+2 \rho f(q)\right\}+\gamma_{n} G\left(q, J x_{n}\right) \\
\leq & \alpha_{n} G\left(q, J x_{1}\right)+\beta_{n} G\left(q, J x_{n}\right)+\gamma_{n} G\left(q, J x_{n}\right)+\xi_{n} \\
= & \alpha_{n} G\left(q, J x_{1}\right)+\left(1-\alpha_{n}\right) G\left(q, J x_{n}\right)+\xi_{n},
\end{aligned}
$$

which shows that $q \in C_{n+1}$. This implies that $\mathcal{F} \subset C_{n+1}$ and so $\mathcal{F} \subset C_{n}$ for all $n \geq 1$.

Step 3. We prove that $\left\{x_{n}\right\}$ is bounded and $\lim _{n \rightarrow \infty} G\left(x_{n}, J x_{1}\right)$ exists.

By Lemma 2.1, we have the result that there exist $x^{*} \in E^{*}$ and $\alpha \in \mathbb{R}$ such that

$$
f(x) \geq\left\langle x, x^{*}\right\rangle+\alpha
$$

Since $x_{n} \in C_{n} \subset E$, it follows that

$$
\begin{aligned}
G\left(x_{n}, J x_{1}\right) & =\left\|x_{n}\right\|^{2}-2\left\langle x_{n}, J x_{1}\right\rangle+\left\|x_{1}\right\|^{2}+2 \rho f\left(x_{n}\right) \\
& \geq\left\|x_{n}\right\|^{2}-2\left\langle x_{n}, J x_{1}\right\rangle+\left\|x_{1}\right\|^{2}+2 \rho\left\langle x_{n}, x^{*}\right\rangle+2 \rho \alpha \\
& =\left\|x_{n}\right\|^{2}-2\left\langle x_{n}, J x_{1}-\rho x^{*}\right\rangle+\left\|x_{1}\right\|^{2}+2 \rho \alpha \\
& \geq\left\|x_{n}\right\|^{2}-2\left\|x_{n}\right\|\left\|J x_{1}-\rho x^{*}\right\|+\left\|x_{1}\right\|^{2}+2 \rho \alpha \\
& =\left(\left\|x_{n}\right\|-\left\|J x_{1}-\rho x^{*}\right\|\right)^{2}+\left\|x_{1}\right\|^{2}-\left\|J x_{1}-\rho x^{*}\right\|^{2}+2 \rho \alpha .
\end{aligned}
$$

For all $q \in \mathcal{F}$ and $x_{n}=\Pi_{C_{n}}^{f_{1}} x_{1}$, we have

$$
\begin{aligned}
G\left(q, J x_{1}\right) & \geq G\left(x_{n}, J x_{1}\right) \\
& \geq\left(\left\|x_{n}\right\|-\left\|J x_{1}-\rho x^{*}\right\|\right)^{2}+\left\|x_{1}\right\|-\left\|J x_{1}-\rho x^{*}\right\|^{2}+2 \rho \alpha .
\end{aligned}
$$

This implies that the sequence $\left\{x_{n}\right\}$ is bounded and so is $\left\{G\left(x_{n}, J x_{1}\right)\right\}$. From (1.2) and Lemma 2.5, we obtain

$$
0 \leq\left(\left\|x_{n+1}\right\|-\left\|x_{n}\right\|\right)^{2} \leq \phi\left(x_{n+1}, x_{n}\right) \leq G\left(x_{n+1}, J x_{1}\right)-G\left(x_{n}, J x_{1}\right)
$$

This shows that $\left\{G\left(x_{n}, J x_{1}\right)\right\}$ is nondecreasing. It follows from the boundedness that $\lim _{n \rightarrow \infty} G\left(x_{n}, J x_{1}\right)$ exists.

Step 4. Next, we prove that $x_{n} \rightarrow \bar{x}, y_{n} \rightarrow \bar{x}$, and $u_{n} \rightarrow \bar{x}$ as $n \rightarrow \infty$, where $\bar{x}$ is some point in $C$.

By (3.4), we obtain

$$
\lim _{n \rightarrow \infty} \phi\left(x_{n+1}, x_{n}\right)=0
$$

Since $\left\{x_{n}\right\}$ is bounded and $E$ is reflexive, we may assume that $x_{n} \rightarrow \bar{x}$ as $n \rightarrow \infty$. Since $C_{n}$ is closed and convex, we find that $\bar{x} \in C_{n}$. From the weak lower semicontinuity of the norm 
and $x_{n}=\Pi_{C_{n}}^{f} x_{1}$, we obtain

$$
\begin{aligned}
G\left(\bar{x}, J x_{1}\right) & =\|\bar{x}\|^{2}-2\left\langle\bar{x}, J x_{1}\right\rangle+\left\|x_{1}\right\|^{2}+2 \rho f(\bar{x}) \\
& \leq \liminf _{n \rightarrow \infty}\left\{\left\|x_{n}\right\|^{2}-2\left\langle x_{n}, J x_{1}\right\rangle+\left\|x_{1}\right\|^{2}+2 \rho f\left(x_{n}\right)\right\} \\
& =\liminf _{n \rightarrow \infty} G\left(x_{n}, J x_{1}\right) \\
& \leq \limsup _{n \rightarrow \infty} G\left(x_{n}, J x_{1}\right) \\
& \leq G\left(\bar{x}, J x_{1}\right),
\end{aligned}
$$

which implies that $\lim _{n \rightarrow \infty} G\left(x_{n}, J x_{1}\right)=G\left(\bar{x}, J x_{1}\right)$. From Lemma 2.5, we obtain

$$
\begin{aligned}
0 & \leq\left(\|\bar{x}\|-\left\|x_{n}\right\|\right)^{2} \\
& \leq \phi\left(\bar{x}, x_{n}\right) \\
& \leq G\left(\bar{x}, J x_{1}\right)-G\left(x_{n}, J x_{1}\right) .
\end{aligned}
$$

Hence we have $\lim _{n \rightarrow \infty}\left\|x_{n}\right\|=\|\bar{x}\|$. In view of the Kadec-Klee property of $E$, we find that

$$
\lim _{n \rightarrow \infty} x_{n}=\bar{x}
$$

And we have

$$
\lim _{n \rightarrow \infty}\left\|x_{n}-x_{n+1}\right\|=0
$$

Since $J$ is uniformly norm-to-norm continuous, it follows that

$$
\lim _{n \rightarrow \infty}\left\|J x_{n}-J x_{n+1}\right\|=0
$$

From $x_{n+1}=\Pi_{C_{n+1}}^{f} x_{1} \in C_{n+1} \subset C_{n}$ and (3.1), we have

$$
G\left(x_{n+1}, J u_{n}\right) \leq \alpha_{n} G\left(x_{n+1}, J x_{1}\right)+\left(1-\alpha_{n}\right) G\left(x_{n+1}, J x_{n}\right)+\xi_{n} .
$$

This is equivalent to the following:

$$
\phi\left(x_{n+1}, u_{n}\right) \leq \alpha_{n} \phi\left(x_{n+1}, x_{1}\right)+\left(1-\alpha_{n}\right) \phi\left(x_{n+1}, x_{n}\right)+\xi_{n} .
$$

Due to (3.5), (3.7), the assumption (ii), and Remark 2.2, we have

$$
\lim _{n \rightarrow \infty} \phi\left(x_{n+1}, u_{n}\right)=0 .
$$

By (1.2), it follows that

$$
\left\|u_{n}\right\| \rightarrow\|\bar{x}\|
$$


as $n \rightarrow \infty$. Since $J$ is uniformly norm-to-norm continuous, we obtain

$$
\left\|J u_{n}\right\| \rightarrow\|J \bar{x}\|
$$

as $n \rightarrow \infty$. This implies that $\left\{\left\|J u_{n}\right\|\right\}$ is bounded in $E^{*}$. Since $E^{*}$ is reflexive, we assume that $J u_{n} \rightarrow \bar{u} \in E^{*}$ as $n \rightarrow \infty$. In view of $J(E)=E^{*}$, there exists $u \in E$ such that $J u=\bar{u}$. This implies that $J u_{n} \rightarrow J u$. We have

$$
\begin{aligned}
\phi\left(x_{n+1}, u_{n}\right) & =\left\|x_{n+1}\right\|^{2}-2\left\langle x_{n+1}, J u_{n}\right\rangle+\left\|u_{n}\right\|^{2} \\
& =\left\|x_{n+1}\right\|^{2}-2\left\langle x_{n+1}, J u_{n}\right\rangle+\left\|J u_{n}\right\|^{2} .
\end{aligned}
$$

Taking $\liminf _{n \rightarrow \infty}$ on both sides of the equality above, this yields

$$
\begin{aligned}
0 & \geq\|\bar{x}\|^{2}-2\langle\bar{x}, \bar{u}\rangle+\|\bar{u}\|^{2} \\
& =\|\bar{x}\|^{2}-2\langle\bar{x}, J u\rangle+\|J u\|^{2} \\
& =\|\bar{x}\|^{2}-2\langle\bar{x}, J u\rangle+\|u\|^{2} \\
& =\phi(\bar{x}, u),
\end{aligned}
$$

which shows that $\bar{x}=u$ and so $J u_{n} \rightarrow J \bar{x}$. It follows from (3.9) and the Kadec-Klee property of $E^{*}$ that $J u_{n} \rightarrow J \bar{x}$ as $n \rightarrow \infty$. Since $J^{-1}$ is norm-weak-continuous, we have

$$
u_{n} \rightarrow \bar{x}
$$

From (3.8), (3.10), and the Kadec-Klee property of $E$, we have

$$
\lim _{n \rightarrow \infty} u_{n}=\bar{x}
$$

On the other hand, we see from the weak lower semicontinuity of the norm that

$$
\begin{aligned}
\phi(q, \bar{x}) & =\|q\|^{2}-2\langle q, J \bar{x}\rangle+\|\bar{x}\|^{2} \\
& \leq \liminf _{n \rightarrow \infty}\left(\|q\|^{2}-2\left\langle q, J u_{n}\right\rangle+\left\|u_{n}\right\|^{2}\right) \\
& =\liminf _{n \rightarrow \infty} \phi\left(q, u_{n}\right) \\
& \leq \limsup _{n \rightarrow \infty} \phi\left(q, u_{n}\right) \\
& =\limsup _{n \rightarrow \infty}\left(\|q\|-2\left\langle q, J u_{n}\right\rangle+\left\|u_{n}\right\|^{2}\right) \\
& \leq \phi(q, \bar{x}),
\end{aligned}
$$

which implies that

$$
\lim _{n \rightarrow \infty} \phi\left(q, u_{n}\right)=\phi(q, \bar{x})
$$


By (3.6) and (3.11), we obtain $\lim _{n \rightarrow \infty}\left\|x_{n}-u_{n}\right\|=0$. The uniform continuity of $J$ on bounded sets gives

$$
\lim _{n \rightarrow \infty}\left\|J x_{n}-J u_{n}\right\|=0
$$

Now, using the definition of $\phi$, we have, for all $q \in \mathcal{F}$,

$$
\begin{aligned}
\phi\left(q, x_{n}\right)-\phi\left(q, u_{n}\right) & =\left\|x_{n}\right\|^{2}-\left\|u_{n}\right\|^{2}-2\left\langle q, J x_{n}-J u_{n}\right\rangle \\
& \leq\left\|x_{n}-u_{n}\right\|\left(\left\|x_{n}\right\|+\left\|u_{n}\right\|\right)+2\|q\|\left\|J x_{n}-J u_{n}\right\| .
\end{aligned}
$$

From (3.13), we obtain

$$
\phi\left(q, x_{n}\right)-\phi\left(q, u_{n}\right) \rightarrow 0
$$

as $n \rightarrow \infty$. By (3.12), it follows that

$$
\lim _{n \rightarrow \infty} \phi\left(q, x_{n}\right)=\phi(q, \bar{x})
$$

Hence, for any $q \in \mathcal{F} \subset C_{n}$, it follows from the convexity of $\|\cdot\|^{2}$ and Lemma 2.3 that

$$
\begin{aligned}
\phi\left(q, u_{n}\right)= & \phi\left(q, T_{r_{n}}^{\theta} y_{n}\right) \\
\leq & \phi\left(q, y_{n}\right) \\
= & \phi\left(q, J^{-1}\left(\alpha_{n} J x_{1}+\beta_{n} J T^{n} x_{n}+\gamma_{n} J x_{n}\right)\right) \\
= & \|q\|^{2}-2\left\langle q, \alpha_{n} J x_{1}+\beta_{n} J T^{n} x_{n}+\gamma_{n} J x_{n}\right\rangle \\
& +\left\|\alpha_{n} J x_{1}+\beta_{n} J T^{n} x_{n}+\gamma_{n} J x_{n}\right\|^{2} \\
\leq & \|q\|-2 \alpha_{n}\left\langle q, J x_{1}\right\rangle-2 \beta_{n}\left\langle q, J T^{n} x_{n}\right\rangle-2 \gamma_{n}\left\langle q, J x_{n}\right\rangle \\
& +\alpha_{n}\left\|J x_{1}\right\|^{2}+\beta_{n}\left\|J T^{n} x_{n}\right\|^{2}+\gamma_{n}\left\|J x_{n}\right\|^{2} \\
= & \alpha_{n} \phi\left(q, x_{1}\right)+\beta_{n} \phi\left(q, T^{n} x_{n}\right)+\gamma_{n} \phi\left(q, x_{n}\right) \\
\leq & \alpha_{n} \phi\left(q, x_{1}\right)+\beta_{n}\left(\phi\left(q, x_{n}\right)+\xi_{n}\right)+\gamma_{n} \phi\left(q, x_{n}\right) \\
\leq & \alpha_{n} \phi\left(q, x_{1}\right)+\left(1-\alpha_{n}\right) \phi\left(q, x_{n}\right)+\xi_{n} .
\end{aligned}
$$

From (3.12), (3.14), (3.15), Remark 2.2, and the assumption (ii), we obtain

$$
\lim _{n \rightarrow \infty} \phi\left(q, y_{n}\right)=\phi(q, \bar{x})
$$

From Lemma 2.3, we see that for any $q \in \mathcal{F}$ and $u_{n}=T_{r_{n}}^{\theta} y_{n}$,

$$
\begin{aligned}
\phi\left(u_{n}, y_{n}\right) & =\phi\left(T_{r_{n}}^{\theta} y_{n}, y_{n}\right) \\
& \leq \phi\left(q, y_{n}\right)-\phi\left(q, T_{r_{n}}^{\theta} y_{n}\right) \\
& =\phi\left(q, y_{n}\right)-\phi\left(q, u_{n}\right) .
\end{aligned}
$$


Taking $n \rightarrow \infty$ on both sides of the inequality above, we have

$$
\lim _{n \rightarrow \infty} \phi\left(u_{n}, y_{n}\right)=0
$$

From (1.2), we have $\left(\left\|u_{n}\right\|-\left\|y_{n}\right\|\right)^{2} \rightarrow 0$ as $n \rightarrow \infty$. By (3.8), we have

$$
\left\|y_{n}\right\| \rightarrow\|\bar{x}\|
$$

as $n \rightarrow \infty$, and so

$$
\left\|J y_{n}\right\| \rightarrow\|J \bar{x}\|
$$

as $n \rightarrow \infty$. That is, $\left\{\left\|J y_{n}\right\|\right\}$ is bounded in $E^{*}$. Since $E^{*}$ is reflexive, we can assume that $J y_{n} \rightarrow y^{*} \in E^{*}$ as $n \rightarrow \infty$. In view of $J(E)=E^{*}$, there exists $y \in E$ such that $J y=y^{*}$. It follows that

$$
\begin{aligned}
\phi\left(u_{n}, y_{n}\right) & =\left\|u_{n}\right\|^{2}-2\left\langle u_{n}, J y_{n}\right\rangle+\left\|y_{n}\right\|^{2} \\
& =\left\|u_{n}\right\|^{2}-2\left\langle u_{n}, J y_{n}\right\rangle+\left\|J y_{n}\right\|^{2} .
\end{aligned}
$$

Taking $\liminf _{n \rightarrow \infty}$ on both sides of the equality above, it follows that

$$
\begin{aligned}
0 & \geq\|\bar{x}\|^{2}-2\left\langle\bar{x}, y^{*}\right\rangle+\left\|y^{*}\right\|^{2} \\
& =\|\bar{x}\|^{2}-2\langle\bar{x}, J y\rangle+\|J y\|^{2} \\
& =\|\bar{x}\|^{2}-2\langle\bar{x}, J y\rangle+\|y\|^{2} \\
& =\phi(\bar{x}, y) .
\end{aligned}
$$

From Remark 1.1, $\bar{x}=y$, i.e., $y^{*}=J \bar{x}$. It follows that $J y_{n} \rightarrow J \bar{x} \in E^{*}$ as $n \rightarrow \infty$. From (3.17) and the Kadec-Klee property of $E^{*}$, we have

$$
J y_{n} \rightarrow J \bar{x}
$$

as $n \rightarrow \infty$. Since $J^{-1}$ is norm-weak*-continuous, $y_{n} \rightarrow \bar{x}$ as $n \rightarrow \infty$. From (3.16) and the Kadec-Klee property of $E$, we have

$$
\lim _{n \rightarrow \infty} y_{n}=\bar{x}
$$

Step 5. We show that $\bar{x} \in \mathcal{F}$.

By Step 4, we get

$$
\lim _{n \rightarrow \infty}\left\|u_{n}-y_{n}\right\|=0
$$

The uniform continuity of $J$ on bounded sets gives

$$
\lim _{n \rightarrow \infty}\left\|J u_{n}-J y_{n}\right\|=0 .
$$


From the assumption $r_{n} \geq a$ and (3.18), we see that $\frac{\left\|u_{n}-J y_{n}\right\|}{r_{n}} \rightarrow 0$ as $n \rightarrow \infty$. But from (A2) and (3.1), we note that

$$
\frac{1}{r_{n}}\left\langle y-u_{n}, J u_{n}-J y_{n}\right\rangle \geq-\theta\left(u_{n}, y\right) \geq \theta\left(y, u_{n}\right), \quad \forall y \in C
$$

and hence

$$
\left\|y-u_{n}\right\| \frac{\left\|J u_{n}-J y_{n}\right\|}{r_{n}} \geq \theta\left(y, u_{n}\right), \quad \forall y \in C,
$$

which implied that $\theta(y, \bar{x}) \leq 0$ for all $y \in C$. Put $y_{t}=t y+(1-t) \bar{x}$ for all $t \in(0,1]$ and $y \in C$. Then we get $y_{t} \in C$ and $\theta\left(y_{t}, \bar{x}\right) \leq 0$. Therefore, from (A1) and (A4), we obtain

$$
\begin{aligned}
0 & =\theta\left(y_{t}, y_{t}\right) \leq t \theta\left(y_{t}, y\right)+(1-t) \theta\left(y_{t}, \bar{x}\right) \\
& \leq t \theta\left(y_{t}, y\right) .
\end{aligned}
$$

Thus, $\theta\left(y_{t}, y\right) \geq 0$ for all $y \in C$. Furthermore, as $t \rightarrow \infty$, we have from (A3) that $\theta(\bar{x}, y) \geq 0$ for all $y \in C$. This implies that $\bar{x} \in E P(\theta)$.

Finally, we show that $\bar{x} \in F(T)$. In view of $y_{n}=J^{-1}\left(\alpha_{n} J x_{1}+\beta_{n} J T^{n} x_{n}+\gamma_{n} J x_{n}\right)$, we find that

$$
J u_{n}-J y_{n}=\alpha_{n}\left(J u_{n}-J x_{1}\right)+\beta_{n}\left(J u_{n}-J T^{n} x_{n}\right)+\gamma_{n}\left(J u_{n}-J x_{n}\right) .
$$

Hence we have

$$
\begin{aligned}
\beta_{n}\left\|J u_{n}-J T^{n} x_{n}\right\| \leq & \left\|J u_{n}-J \bar{x}\right\|+\left\|J \bar{x}-J y_{n}\right\|+\alpha_{n}\left\|J u_{n}-J x_{1}\right\| \\
& +\gamma_{n}\left\|J u_{n}-J x_{n}\right\| .
\end{aligned}
$$

From the assumptions (ii), (iii), and (3.13), we have

$$
\lim _{n \rightarrow \infty}\left\|J u_{n}-J T^{n} x_{n}\right\|=0
$$

Notice that

$$
\left\|J T^{n} x_{n}-J \bar{x}\right\| \leq\left\|J T^{n} x_{n}-J u_{n}\right\|+\left\|J u_{n}-J \bar{x}\right\| .
$$

This implies from (3.19) that

$$
\lim _{n \rightarrow \infty}\left\|J T^{n} x_{n}-J \bar{x}\right\|=0 .
$$

The demicontinuity of $J^{-1}: E^{*} \rightarrow E$ implies that $T^{n} x_{n} \rightarrow \bar{x}$ as $n \rightarrow \infty$. We have

$$
\left|\left\|T^{n} x_{n}\right\|-\|\bar{x}\|\right|=\left|\left\|J T^{n} x_{n}\right\|-\|J \bar{x}\|\right| \leq\left\|J T^{n} x_{n}-J \bar{x}\right\| .
$$

With the aid of (3.20), we see that $\lim _{n \rightarrow \infty}\left\|T^{n} x_{n}\right\|=\|\bar{x}\|$. Since $E$ has the Kadec-Klee property, we find that

$$
\lim _{n \rightarrow \infty}\left\|T^{n} x_{n}-\bar{x}\right\|=0 .
$$


Since

$$
\left\|T^{n+1} x_{n}-\bar{x}\right\| \leq\left\|T^{n+1} x_{n}-T^{n} x_{n}\right\|+\left\|T^{n} x_{n}-\bar{x}\right\|
$$

we find from (3.21) and the asymptotic regularity of $T$ that

$$
\lim _{n \rightarrow \infty}\left\|T^{n+1} x_{n}-\bar{x}\right\|=0
$$

i.e., $T T^{n} x_{n}-\bar{x} \rightarrow 0$ as $n \rightarrow \infty$. It follows from the closedness of $T$ that $T \bar{x}=\bar{x}$. So, $\bar{x} \in F(T)$ and hence $\bar{x} \in \mathcal{F}=F(T) \cap E P(\theta)$.

Step 6. We show that $\bar{x}=\Pi_{\mathcal{F}}^{f} x_{1}$ and so $x_{n} \rightarrow \Pi_{\mathcal{F}}^{f} x_{1}$ as $n \rightarrow \infty$.

Since $\mathcal{F}$ is a closed convex set, it follows from Lemma 2.2 that $\Pi_{\mathcal{F}}^{f} x_{1}$ is single-valued, which is denoted by $\tilde{x}$. By the definition of $x_{n}=\Pi_{C_{n}}^{f} x_{1}$ and $\tilde{x} \in \mathcal{F} \subset C_{n}$, we also have

$$
G\left(x_{n}, J x_{1}\right) \leq G\left(\tilde{x}, J x_{1}\right)
$$

for all $n \geq 1$. By the definition of $G$, we know that for any $x \in E, G(u, J x)$ is convex and lower semicontinuous with respect to $u$ and so

$$
\begin{aligned}
G\left(\bar{x}, J x_{1}\right) & \leq \liminf _{n \rightarrow \infty} G\left(x_{n}, J x_{1}\right) \\
& \leq \limsup _{n \rightarrow \infty} G\left(x_{n}, J x_{1}\right) \\
& \leq G\left(\tilde{x}, J x_{1}\right) .
\end{aligned}
$$

From the definition of $\Pi_{\mathcal{F}}^{f} x_{1}$ and $\bar{x} \in \mathcal{F}$, we conclude that

$$
\bar{x}=\tilde{x}=\Pi_{\mathcal{F}}^{f} x_{1}
$$

and $x_{n} \rightarrow \bar{x}=\Pi_{\mathcal{F}}^{f} x_{1}$ as $n \rightarrow \infty$. This completes the proof.

\section{Remark 3.1}

(i) If $f=0$, then $G(x, J y)=\phi(x, y)$ and $\Pi_{C_{n}}^{f}=\Pi_{C_{n}}$.

(ii) If we take $f=0, \theta=0, u_{n}=y_{n}$, and $\alpha_{n}=0$ for all $n \in \mathbb{N}$, then the iterative scheme (3.1) reduces to the following scheme:

$$
\left\{\begin{array}{l}
x_{0} \in E \text { chosen arbitrarily, } \\
C_{1}=C \\
y_{n}=J^{-1}\left(\beta_{n} J T^{n} x_{n}+\left(1-\beta_{n}\right) J x_{n}\right), \\
C_{n+1}=\left\{z \in C_{n}: \phi\left(z, y_{n}\right) \leq \phi\left(z, x_{n}\right)+\xi_{n}\right\}, \\
x_{n+1}=\Pi_{C_{n+1}} x_{1}, \quad \forall n \geq 1,
\end{array}\right.
$$

where $\xi_{n}=\max \left\{0, \sup _{p \in F(T), x \in C}\left(\phi\left(p, T^{n} x\right)-\phi(p, x)\right)\right\}$, which is the algorithm introduced by Hao [10] and an improvement to (1.3).

If $T$ is quasi- $\phi$-nonexpansive, then Theorem 3.1 is reduced to following without the boundedness of $F(T)$ and the asymptotically regularity of $T$. 
Corollary 3.1 Let E be a uniformly smooth and strictly convex Banach space with the Kadec-Klee property. Let $C$ be a nonempty closed convex subset of $E$. Let $\theta$ be a bifunction from $C \times C$ to $\mathbb{R}$ satisfying the conditions (A1)-(A4). Let $T: C \rightarrow C$ be a closed and quasi$\phi$-nonexpansive mapping. Assume that $\mathcal{F}=F(T) \cap E P(\theta)$ is nonempty. Let $f: E \rightarrow \mathbb{R}^{+}$be a convex and lower semicontinuous function with $C \subset \operatorname{int}(D(f))$ and $f(0)=0$. Let $\left\{\alpha_{n}\right\}$ be a sequence in $[0,1]$ and $\left\{\beta_{n}\right\},\left\{\gamma_{n}\right\}$ be sequences in $(0,1)$ satisfying the following conditions:

(i) $\alpha_{n}+\beta_{n}+\gamma_{n}=1$;

(ii) $\lim _{n \rightarrow \infty} \alpha_{n}=0$;

(iii) $0<\liminf _{n \rightarrow \infty} \beta_{n} \leq \limsup _{n \rightarrow \infty} \beta_{n}<1$.

Let $\left\{x_{n}\right\}$ be a sequence generated by

$$
\left\{\begin{array}{l}
x_{1} \in E \text { chosen arbitrarily, } \\
C_{1}=C, \\
y_{n}=J^{-1}\left(\alpha_{n} J x_{1}+\beta_{n} J T x_{n}+\gamma_{n} J x_{n}\right) \\
u_{n} \in C \text { such that } \theta\left(u_{n}, y\right)+\frac{1}{r_{n}}\left\langle y-u_{n}, J u_{n}-J y_{n}\right\rangle \geq 0, \quad \forall y \in C, \\
C_{n+1}=\left\{z \in C_{n}: G\left(z, J u_{n}\right) \leq \alpha_{n} G\left(z, J x_{1}\right)+\left(1-\alpha_{n}\right) G\left(z, J x_{n}\right)\right\}, \\
x_{n+1}=\Pi_{C_{n+1}}^{f} x_{1}, \quad \forall n \geq 1,
\end{array}\right.
$$

where $\left\{r_{n}\right\}$ is a real sequence in $[a, \infty)$ for some $a>0$ and $\Pi_{C_{n+1}}^{f}$ is the generalized $f$ projection operator. Then $\left\{x_{n}\right\}$ converges strongly to $\Pi_{\mathcal{F}}^{f} x_{1}$.

\section{Remark 3.2}

(i) By Remark 3.1, Theorem 3.1 extends Theorem 2.1 of Hao [10].

(ii) Theorem 3.1 generalizes Theorem 3.1 of Matsushita and Takahashi [9] in the following respects:

- from the relatively nonexpansive mapping to the asymptotically quasi- $\phi$-nonexpansive mapping in the intermediate sense;

- from a uniformly convex and uniformly smooth Banach space to a uniformly smooth and strictly convex Banach space with the Kadec-Klee property;

(iii) in view of the mappings and the frame work of the spaces, Theorem 3.1 generalizes and improves Theorem 3.1 of Ma et al. [16], Theorem 3.1 of Qin et al. [17], Theorem 3.1 of Qing and Lv [18] and Theorem 3.1 of Saewan [19].

We now provide a nontrivial family of mappings satisfying the conditions of Theorem 3.1.

Example 3.1 Let $E=\mathbb{R}$ with the standard norm $\|\cdot\|=|\cdot|$ and $C=[0,1]$. Let $T: C \rightarrow C$ be a mapping defined by

$$
T x= \begin{cases}\frac{1}{2} x, & x \in\left[0, \frac{1}{2}\right], \\ 0, & x \in\left(\frac{1}{2}, 1\right] .\end{cases}
$$


We first show that $T$ is an asymptotically quasi- $\phi$-nonexpansive mapping in the intermediate sense with $F(T)=\{0\} \neq \phi$. In fact, for $p=0 \in F(T)$, we have

$$
\begin{aligned}
\phi\left(p, T^{n} x\right) & =\left|0-T^{n} x\right|^{2} \\
& =\frac{1}{2^{2 n}}|x|^{2} \\
& \leq|0-x|^{2}=\phi(p, x), \quad \forall x \in\left[0, \frac{1}{2}\right]
\end{aligned}
$$

and

$$
\begin{aligned}
\phi\left(p, T^{n} x\right) & =\left|0-T^{n} x\right|^{2} \\
& =0 \\
& \leq|0-x|^{2}=\phi(p, x), \quad \forall x \in\left(\frac{1}{2}, 1\right] .
\end{aligned}
$$

Therefore, we have

$$
\limsup _{n \rightarrow \infty} \sup _{p \in F(T), x \in C}\left(\phi\left(p, T^{n} x\right)-\phi(p, x)\right) \leq 0
$$

Next, we define a bifunction $\theta: C \times C \rightarrow \mathbb{R}$ satisfying the conditions (A1)-(A4) by

$$
\theta(x, y)=y^{2}-x^{2}
$$

Then the set of solutions $E P(\theta)$ to the equilibrium problem for $\theta$ is obviously $\{0\}$. Since $\mathcal{F}=F(T) \cap E P(\theta) \neq \phi$ and $F(T)$ is bounded, it follows from Theorem 3.1 that the sequence defined by (3.1) converges strongly to $\Pi_{\mathcal{F}}^{f} x_{1}$.

\section{Competing interests}

The author declares that he has no competing interests.

\section{Author's contributions}

JUJ conceived of the study, its design, and its coordination. The author read and approved the final manuscript.

\section{Acknowledgements}

The author is grateful to the anonymous referees for useful suggestions, which improved the contents of the article.

Received: 28 April 2014 Accepted: 2 September 2014 Published: 24 Sep 2014

\section{References}

1. Goebel, K, Kirk, WA: A fixed point theorem for asymptotically nonexpansive mappings. Proc. Am. Math. Soc. 35, 171-174 (1972)

2. Bruck, RE, Kuczumow, T, Reich, S: Convergence of iterates of asymptotically nonexpansive mappings in Banach spaces with the uniform Opial property. Colloq. Math. 65(2), 169-179 (1993)

3. Kirk, WA: Fixed point theorems for non-Lipschitzian mappings of asymptotically nonexpansive type. Isr. J. Math. 17, 339-346 (1974)

4. Chidume, $\mathrm{CE}$, Ofoedu, EU, Zegeye, $\mathrm{H}$ : Strong and weak convergence theorem for asymptotically nonexpansive mappings. J. Math. Anal. Appl. 280, 364-374 (2003)

5. Górnicki, J: Weak convergence theorems for asymptotically nonexpansive mappings in uniformly convex Banach spaces. Comment. Math. Univ. Carol. 30, 249-252 (1989)

6. Schu, J: Weak and strong convergence to fixed points of asymptotically nonexpansive mappings. Bull. Aust. Math Soc. 43, 153-159 (1991) 
7. Alber, Yl: Metric and generalized projection operators in Banach spaces: properties and applications. In: Kartsatos, AG (ed.) Theory and Applications of Nonlinear Operators of Accretive and Monotone Type. Lecture Notes in Pure and Appl. Math., vol. 178, pp. 15-50. Dekker, New York (1996)

8. Su, Y, Wang, D, Shang, M: Strong convergence of monotone hybrid algorithm for hemi-relatively nonexpansive mappings. Fixed Point Theory Appl. 2008, 284613 (2008)

9. Matsushita, S, Takahashi, W: A strong convergence theorem for relatively nonexpansive mappings in Banach spaces. J. Approx. Theory 134, 257-266 (2005)

10. Hao, Y: Some results on a modified Mann iterative scheme in a reflexive Banach space. Fixed Point Theory Appl. 2013 $227(2013)$

11. Cioranescu, I: Geometry of Banach Spaces, Duality Mappings and Nonlinear Problems. Kluwer Academic, Dordrecht (1990)

12. $\mathrm{Wu}, \mathrm{KQ}$, Huang, NJ: The generalized $f$-projection operator with an application. Bull. Aust. Math. Soc. 73, 307-317 (2006)

13. Li, X, Huang, N, O'Regan, D: Strong convergence theorems for relative nonexpansive mappings in Banach spaces with applications. Comput. Math. Appl. 60, 1322-1331 (2010)

14. Deimling, K: Nonlinear Functional Analysis. Springer, Berlin (1985)

15. Takahashi, W, Zembayashi, K: Strong and weak convergence theorems for equilibrium problems and relatively nonexpansive mappings in Banach spaces. Nonlinear Anal. 70, 45-57 (2009)

16. Ma, Z, Wang, L, Chang, SS: Strong convergence theorem for quasi- $\phi$-asymptotically nonexpansive mappings in the intermediate sense in Banach spaces. J. Inequal. Appl. 2013, 306 (2013)

17. Qin, X, Cho, SY, Wang, L: Algorithms for treating equilibrium and fixed point problems. Fixed Point Theory Appl. 2013 $308(2013)$

18. Qing, Y, Lv, S: A strong convergence theorem for solutions of equilibrium problems and asymptotically quasi- $\phi$-nonexpansive mappings in the intermediate sense. Fixed Point Theory Appl. 2013, 305 (2013)

19. Saewan, S: Strong convergence theorem for total quasi- $\phi$-asymptotically nonexpansive mappings in a Banach space Fixed Point Theory Appl. 2013, 297 (2013)

10.1186/1687-1812-2014-199

Cite this article as: Jeong: Convergence theorems for equilibrium problem and asymptotically

quasi- $\phi$-nonexpansive mappings in the intermediate sense. Fixed Point Theory and Applications 2014, 2014:199

\section{Submit your manuscript to a SpringerOpen ${ }^{\odot}$ journal and benefit from:}

- Convenient online submission

- Rigorous peer review

- Immediate publication on acceptance

Open access: articles freely available online

High visibility within the field

- Retaining the copyright to your article 